\title{
HUBUNGAN PROFIL PELAKU PERJALANAN DENGAN PERILAKU PERJALANAN TERHADAP PUSAT PERBELANJAAN MODERN DI KAWASAN PERKOTAAN YOGYAKARTA
}

\author{
Ratno Tanjung Nasrulloh ${ }^{1}$ Novi Maulida Ni'mah ${ }^{2}$ \\ ${ }^{12}$ Program Studi Perencanaan Wilayah dan Kota \\ ${ }^{12}$ Institut Teknologi Nasional Yogyakarta \\ ${ }^{1}$ Email: ratnotanjunk@gmail.com
}

\begin{abstract}
Yogyakarta Urban Area (KPY) is currently developing rapidly to support the development of urban functions and services in Yogyakarta, one of which is the trade and services sector. This can be seen from the number of modern shopping centers in KPY. The interaction between land and transportation has been accepted by researchers from various disciplines for decades. Therefore, examining the travel behavior towards the shopping center becomes one of the bases in planning urban morphology and rather the morphology influences the travel behavior of the community. This study seeks to examine the travel pattern of people to shopping centers in the Yogyakarta urban area with case studies of Mall Ambarukmo Plaza, Lippo Mall, and Jogja City Mall. The research method used is cross classification with variables consisting of the profile of the traveler and behavior. Based on the analysis, the profile of the traveler to the modern mall center (gender, age, education level, occupation, income and place of residence (domicile) has no relationship to his travel behavior (frequency, intention, time) in KPY. Mostly or an average of more than $60 \%$ of the trip attractions still come from within KPY.
\end{abstract}

Keywords: Yogyakarta Urban Area, Modern Shopping Center, Travel Pattern, Travel Behaviour

\begin{abstract}
Abstrak
Kawasan Perkotaan Yogyakarta (KPY) saat ini berkembang dengan pesat untuk mendukung perkembangan fungsi dan layanan perkotaan di Yogykarta, salah satunya adalah sektor perdagangan dan jasa. Hal ini terlihat dengan banyaknya pembangunan pusat-pusat perbelanjaan modern di KPY. Interaksi antara penggunaan lahan dan transportasi telah diakui oleh para peneliti dari berbagai disiplin ilmu selama beberapa decade. Oleh karena itu, mengkaji perilaku perjalanan terhadap pusat perbelanjaan menjadi salah satu dasar dalam merencanakan morfologi perkotaan dan sebaliknya morfologi perkotaan berpengaruh terhadap perilaku perjalanan masyarakat. Penelitian ini berupaya untuk mengkaji karakteristik perjalanan masyarakat terhadap pusat perbelanjaan modern di Kawasan Perkotaan Yogyakarta dengan studi kasus Mall Ambarukmo Plaza, Lippo Mall, dan Jogja City Mall. Metode penelitian yang digunakan adalah klasifikasi silang dengan variabel terdiri atas profil pelaku perjalanan dan perilaku perjalanan. Berdasarkan analisis maka dapat disimpulkan bahwa profil pelaku perjalanan terhadap pusat perbelanjaan modern Mall (jenis kelamin, usia, tingkat pendidikan, pekerjaan, pendapatan dan tempat tinggal (domisili) tidak memiliki hubungan terhadap perilaku perjalanannya (frekuensi, maksud, waktu) di KPY. Selain itu, sebagian besar atau rata-rata lebih dari $60 \%$ tarikan perjalanan masih berasal dari dalam KPY.
\end{abstract}

Kata Kunci : Kawasan Perkotaan Yogyakarta, Pusat Perbelanjaan Modern, Pola Perjalanan, Perilaku Perjalanan

\section{Latar Belakang}

Kota Yogyakarta sebagai salah satu kota besar di Indonesia mengalami pertumbuhan dan perkembangan yang cukup pesat. Pertumbuhan penduduk ini disebabkan tingginya arus urbanisasi ke pusat kota, sebagai konsekuensi dari pengembangan Kota Yogyakarta yang terpusat. Perkembangan yang terpusat ini menyebabkan terkonsentrasinya pertumbuhan ekonomi perkotaan dan masih membaurnya fungsi primer dan sekunder sehingga orientasi penduduk ke dalam kota sangat tinggi. Perkembangan fungsi Kota Yogyakarta yang semakin tinggi intensitasnya dihadapkan pada keterbatasan lahan di pusat kota yang mengakibatkan sulitnya memperoleh lahan untuk mewadahi tuntutan kehidupan kota. Hal ini berakibat pada berkembangnya Kawasan Perkotaan Yogyakarta (KPY) yang saat ini berkembang dengan pesat untuk mendukung perkembangan fungsi dan layanan perkotaan di Yogykarta.

Fenomena perembetan fungsi perkotaan ke arah luar, yaitu ke daerah pinggiran kota, terutama untuk memenuhi kebutuhan permukiman (Yunus, 2006). Namun demikian, secara fungsional KPY berkembang juga untuk mendukung perkembangan 
sektor perdagangan dan jasa Kota Yogyakarta. Hal ini terbukti dengan banyaknya pembangunan pusat-pusat perbelanjaan berbasis modern atau ritel. Pembangunan pusat perbelanjaan modern dianggap memberikan dampak positif bagi kota, terutama jika dilihat dari sudut pandang ekonomi, seperti penyerapan tenaga kerja dan sumbangan pajak. Namun, keberadaan pusat perbelanjaan modern penting untuk dipelajari dalam konteks perencanaan wilayah dan kota karena dianggap berkontribusi pada perkembangan kota. Pertumbuhan dan tingginya keberadaan ritel mampu mempengaruhi morfologi suatu kota. Sektor ritel mampu mempengaruhi perilaku spasial dan pergerakan masyarakat di dalam maupun di luar kota tersebut. Pertumbuhan ritel yang semakin tinggi berpotensi meningkatkan penggunaan kendaraan pribadi yang berakibat pada kemacetan lalu lintas.

Interaksi antara penggunaan lahan dan transportasi telah diakui oleh para peneliti dari berbagai disiplin ilmu selama beberapa dekade (Zhou dan Kockelman, 2005). Oleh karena itu, mengkaji perilaku perjalanan menjadi salah satu dasar dalam merencanakan morfologi perkotaan dan sebaliknya morfologi perkotaan berpengaruh terhadap perilaku perjalanan masyarakat (Boarnet dan Crane, 2001). Dalam beberapa tahun terakhir, bermunculan pusat perbelanjaan modern baru di Kawasan Perkotaan Yogyakarta, seperti Lippo Mall, Jogja City Mall, Hartono Mall, Sahid Yogya Lifestyle City, dan lainlain. Berkembangnya kawasan perdagangan dan jasa baru tersebut membuat isu dan permasalahan Kawasan Perkotaan Yogyakarta di masa depan perlu diantisipasi. Terlebih dengan peningkatan perilaku perjalanan akhir pekan dimana salah satunya telah berdampak pada sulitnya menyediakan pelayanan transportasi yang efektif (Ulfa dan Suwandono, 2014). Oleh karena itu, penelitian ini berupaya untuk mengkaji karakteristik perjalanan masyarakat terhadap pusat perbelanjaan modern di Kawasan Perkotaan Yogyakarta untuk mengantisipasi perkembangan fisik kota yang akan datang. Dalam penelitian ini, identifikasi karakteristik perjalanan akan menggunakan pendekatan 'individual factor' dengan mempertimbangkan profil individu dari pelaku perjalanan sehingga menentukan perilaku perjalanan (Kutter, 1973).

\section{Ruang Lingkup}

Lingkup Wilayah

Ruang lingkup wilayah yang akan diteliti yaitu secara geografis berada di Kawasan Perkotaan
Yogyakarta. Penelitian akan mengambil studi kasus pada 3 pusat perbelanjaan modern yaitu Mall Ambarukmo Plaza, Lippo Mall, dan Jogja City Mall.

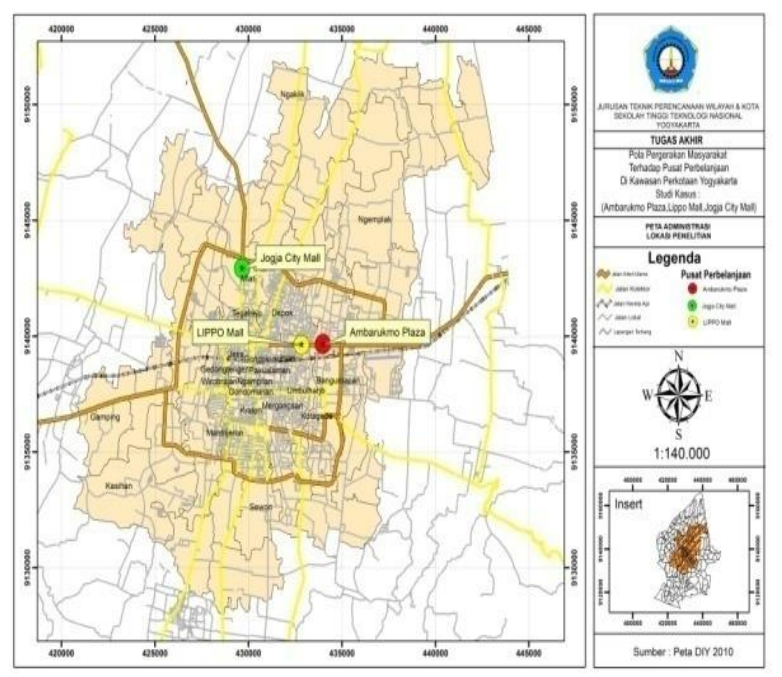

Gambar 1. Lokasi Studi Penelitian

\section{Lingkup Materi}

Dalam mendukung penelitian maka materi pembahasan diuraikan dalam penelitian ini antara lain:

1) Karateristik perjalanan adalah bentuk arus pergerakan masyarakat yang bergerak dari zona asal ke zona tujuan.

2) Kawasan Perkotaan adalah wilayah yang mempunyai kawasan sebagai tempat permukiman perkotaan, pemusatan, dan distribusi pelayanan pemerintahan, pelayanan sosial dan kegiatan ekonomi.

3) Pusat perbelanjaan merupakan tempat perdagangan eceran yang lokasinya digabung dalam satu bangunan.

\section{Metodologi Penelitian}

\section{Teknik Analisis}

Metode pendekatan yang digunakan adalah klasifikasi silang. Klasifikasi silang adalah salah satu analisis statistik korelasional yang digunakan untuk melihat hubungan antar variabel penelitian. Dalam penelitian ini variabel terdiri atas profil pelaku perjalanan dan perilaku perjalanan. Profil perilaku terdiri atas pendapatan, pekerjaan, usia, dan domisili (wilayah asal). Sedangkan untuk perilaku terdiri atas frekuensi kunjungan, maksud melakukan perjalanan, dan waktu kunjungan. Dalam penelitian ini, hipotesis (Ho) adalah tidak ada hubungan antara profil dengan perilaku perjalanan. Jika hasil chi square hitung < chi square tabel maka Ho diterima. 
Teknik Pengambilan Sampel

a) Populasi

Seluruh pengunjung mall di lokasi penelitian.

b) Sampel

Karena populasi tidak diketahui maka pengambilan sampel dilakukan dengan menggunakan rumus sebagai berikut (Arikunto, 2002):

$$
\begin{aligned}
& n=\left[\frac{Z_{\alpha / 2}}{E}\right]^{2} \\
& n=\left[\frac{1,96}{0,20}\right] \\
& \mathrm{n}=96 \text { responden }
\end{aligned}
$$

Keterangan :

$\mathrm{N}=$ Ukuran Sampel

$\mathrm{Za} / 2=$ Nilai standar daftar luar normal standar bagaimana tingkat kepercayaan (a) $95 \%$.
$\mathrm{E}=$ Tingkat ketetapan yang digunakan dengan mengemukakan besarnya error maksimum secara $20 \%$.

Sedangkan teknik pengambilan sampel pada penelitian ini adalah menggunakan metode accidental sampling, dimana untuk memperoleh data peneliti menemui subyek yaitu orang-orang yang secara kebetulan dijumpai pada saat berkunjung melakukan penelitian hingga mencapai jumlah yang dianggap cukup bagi peneliti. Dengan 3 studi kasus maka pengambilan sampel dilakukan secara proporsional.

\section{Hasil Dan Pembahasan \\ Analisis Klasifikasi Silang}

Hasil analisis klasifikasi silang secara detail dapat dilihat pada Tabel 1 hingga 3 (Analisis, 2016)

\begin{tabular}{|c|c|c|c|c|}
\hline \multicolumn{2}{|c|}{ Hubungan } & \multicolumn{3}{|c|}{ Hasil Klasifikasi Silang } \\
\hline Profil & Perilaku & Chi-Square hitung & Chi-Square table & Kesimpulan \\
\hline \multirow[t]{3}{*}{ Pendapatan } & Frekuensi & 16.624 & 31.410 & tidak ada hubungan \\
\hline & Maksud & 29.750 & 24.996 & ada hubungan \\
\hline & Waktu & 22.681 & 24.996 & tidak ada hubungan \\
\hline \multirow[t]{3}{*}{ Pekerjaan } & Frekuensi & 26.712 & 26.296 & ada hubungan \\
\hline & Maksud & 14.859 & 21.026 & tidak ada hubungan \\
\hline & Waktu & 12.078 & 21.026 & tidak ada hubungan \\
\hline \multirow[t]{3}{*}{ Usia } & Frekuensi & 4.082 & 15.507 & tidak ada hubungan \\
\hline & Maksud & 11.316 & 12.592 & tidak ada hubungan \\
\hline & Waktu & 3.524 & 12.592 & tidak ada hubungan \\
\hline \multirow[t]{3}{*}{ Wilayah Asal } & Frekuensi & 13.022 & 26.296 & tidak ada hubungan \\
\hline & Maksud & 3.906 & 21.026 & tidak ada hubungan \\
\hline & Waktu & 9.640 & 21.026 & tidak ada hubungan \\
\hline
\end{tabular}
dengan data terlampir.

Tabel 1. Hasil Analisis Klasifikasi Silang di Mall Ambarukmo Plaza

\begin{tabular}{|c|c|c|c|c|}
\hline \multicolumn{2}{|c|}{ Hubungan } & \multicolumn{3}{|c|}{ Hasil Klasifikasi Silang } \\
\hline Profil & Perilaku & Chi-Square hitung & Chi-Square table & Kesimpulan \\
\hline \multirow[t]{3}{*}{ Pendapatan } & Frekuensi & 28.912 & 31.410 & tidak ada hubungan \\
\hline & Maksud & 20.368 & 24.996 & tidak ada hubungan \\
\hline & Waktu & 27.908 & 31.410 & tidak ada hubungan \\
\hline \multirow[t]{3}{*}{ Pekerjaan } & Frekuensi & 23.160 & 26.296 & tidak ada hubungan \\
\hline & Maksud & 22.240 & 21.026 & ada hubungan \\
\hline & Waktu & 22.983 & 26.296 & tidak ada hubungan \\
\hline \multirow[t]{3}{*}{ Usia } & Frekuensi & 14.355 & 21.026 & tidak ada hubungan \\
\hline & Maksud & 26.494 & 16.919 & ada hubungan \\
\hline & Waktu & 11.199 & 21.026 & tidak ada hubungan \\
\hline \multirow[t]{3}{*}{ Wilayah Asal } & Frekuensi & 7.840 & 21.026 & tidak ada hubungan \\
\hline & Maksud & 8.933 & 16.919 & tidak ada hubungan \\
\hline & Waktu & 7.088 & 21.026 & tidak ada hubungan \\
\hline
\end{tabular}

Tabel 2. Hasil Analisis Klasifikasi Silang di Lippo Mall

Tabel 3. Hasil Analisis Klasifikasi Silang di Jogja City Mall

\begin{tabular}{|c|l|r|r|r|}
\hline \multicolumn{2}{|c|}{ Hubungan } & \multicolumn{3}{c|}{ Hasil Klasifikasi Silang } \\
\hline Profil & Perilaku & Chi-Square hitung & Chi-Square table & Kesimpulan \\
\hline Pendapatan & Frekuensi & 19.556 & 31.410 & tidak ada hubungan \\
\hline
\end{tabular}




\begin{tabular}{|l|l|r|r|l|}
\hline \multicolumn{2}{|c|}{ Hubungan } & \multicolumn{3}{c|}{ Hasil Klasifikasi Silang } \\
\hline \multirow{4}{*}{ Profil } & \multicolumn{1}{|c|}{ Perilaku } & Chi-Square hitung & Chi-Square table & \multicolumn{1}{c|}{ Kesimpulan } \\
\hline \multirow{3}{*}{ Pekerjaan } & Maksud & 26.230 & 31.410 & tidak ada hubungan \\
\cline { 2 - 5 } & Waktu & 29.794 & 31.410 & tidak ada hubungan \\
\cline { 2 - 5 } & Frekuensi & 16.084 & 31.410 & tidak ada hubungan \\
\cline { 2 - 5 } & Maksud & 13.658 & 31.410 & tidak ada hubungan \\
\cline { 2 - 5 } & Waktu & 24.770 & 31.410 & tidak ada hubungan \\
\hline \multirow{3}{*}{ Usia } & Frekuensi & 11.087 & 21.026 & tidak ada hubungan \\
\cline { 2 - 5 } & Maksud & 14.406 & 21.026 & tidak ada hubungan \\
\cline { 2 - 5 } & Waktu & 13.284 & 21.026 & tidak ada hubungan \\
\hline & Frekuensi & 7.840 & 21.026 & tidak ada hubungan \\
\cline { 2 - 5 } & Maksud & 26.865 & 26.296 & ada hubungan \\
\cline { 2 - 5 } & Waktu & 13.235 & 26.296 & tidak ada hubungan \\
\hline
\end{tabular}

Karakteristik Perjalanan terhadap Pusat Perbelanjaan Modern

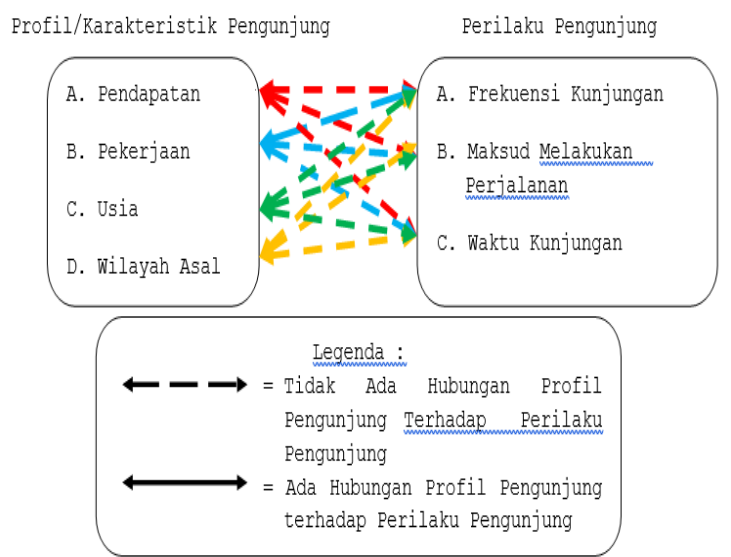

\section{Gambar 2. Karakteristik Perjalanan Terhadap Pusat Perbelanjaan Modern di KPY}

Berdasarkan hasil analisis klasifikasi silang, secara umum mayoritas tidak ada hubungan antara profil pengunjung terhadap perilaku pengunjung di masing-masing mall. Namun demikian dari 12 analisis klasifikasi silang terhadap variabel terdapat 5 klasifikasi silang yang secara spesifik menyatakan ada hubungan yaitu Pendapatan terhadap Maksud Perjalanan dan Pekerjaan terhadap Frekuensi Kunjungan di Ambarrukmo Plaza, Pekerjaan terhadap Maksud Perjalanan dan Usia terhadap Maksud Perjalanan di Lippo Mall, dan Wilayah Asal terhadap Maksud Melakukan Perjalanan di Jogja City Mall.

\section{Hasil Tarikan Perjalanan}

\section{a) Ambarukmo Plaza}

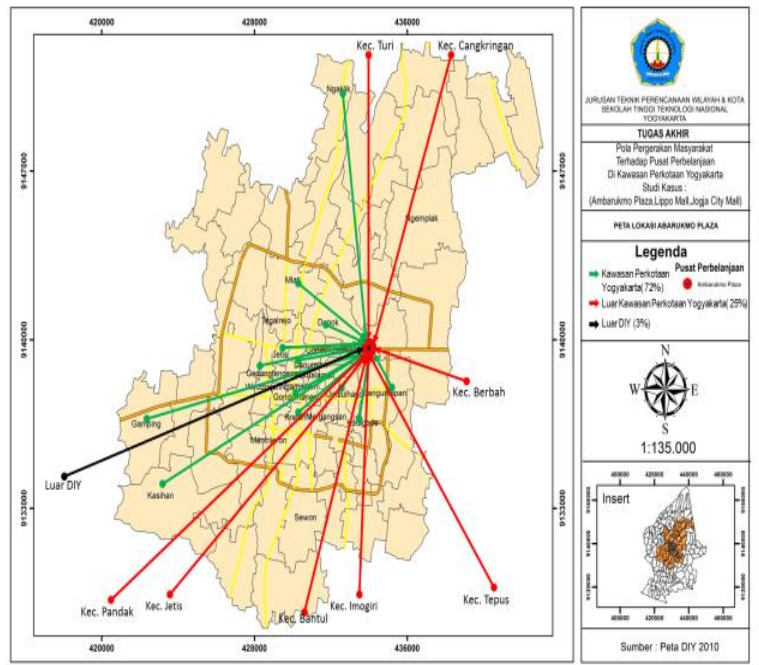

Gambar 3. Peta Pengunjung Ambarukmo Plaza Sumber : Hasil Analisis, 2016

Berdasarkan peta di atas dapat terlihat bahwa tarikan perjalanan pengunjung mall Ambarukmo Plaza paling banyak berasal dari Kawasan Perkotaan Yogyakarta sebesar 72\%, dari Luar KPY sebesar 25\% dan luar DIY sebesar $3 \%$.

\section{b) Lippo Mall}

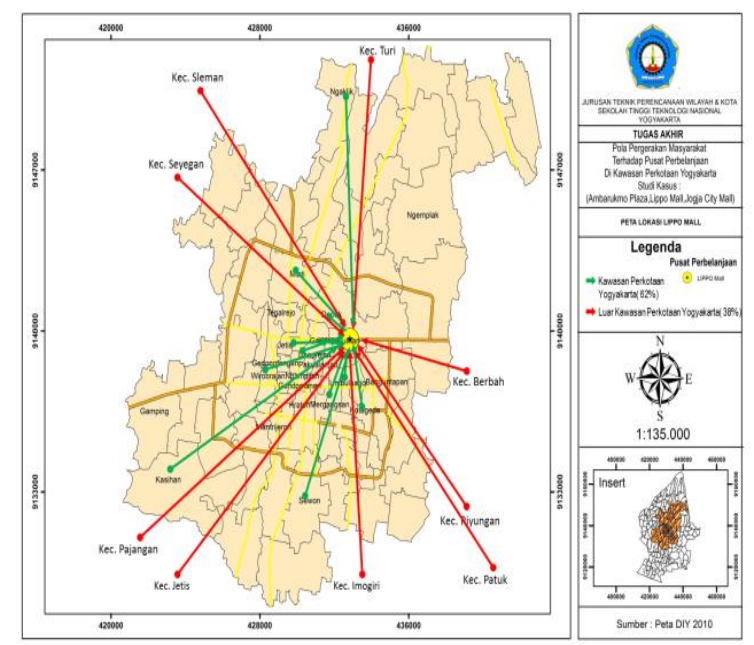

Gambar 4. Peta Pengunjung Lippo Mall 
Berdasarkan peta di atas dapat terlihat bahwa tarikan perjalanan pengunjung Lippo Mall paling banyak berasal dari Kawasan Perkotaan Yogyakarta sebesar $62 \%$ dan dari Luar KPY sebesar 38\%.

\section{c) Jogja City Mall}

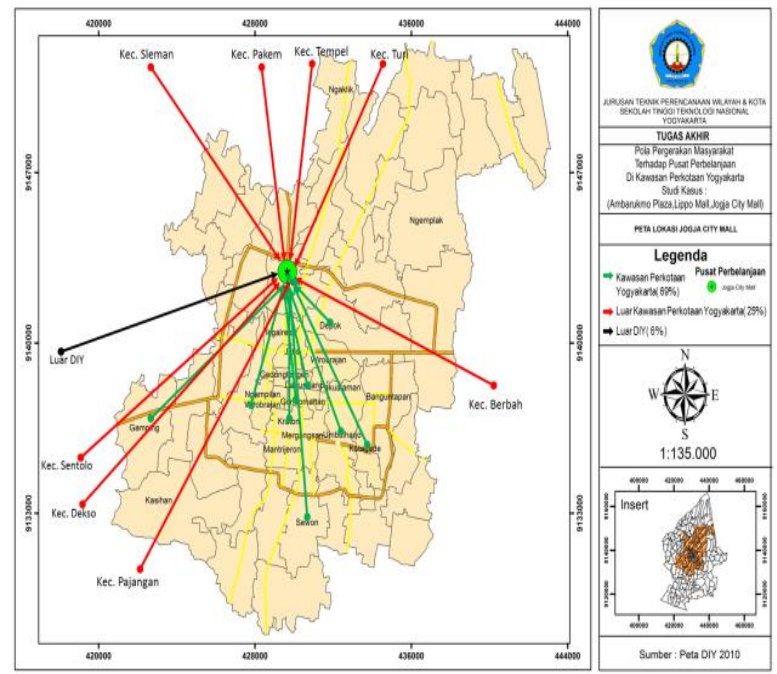

Gambar 5. Peta Pengunjung Jogja City Mall

Berdasarkan peta di atas dapat terlihat bahwa tarikan perjalanan pengunjung Jogja City Mall paling banyak berasal dari Kawasan Perkotaan Yogyakarta sebesar 69\%, dari Luar KPY sebesar 25\% dan luar DIY sebesar 6\%.

\section{Kesimpulan}

Berdasarkan analisis maka dapat disimpulkan bahwa profil pelaku perjalanan terhadap pusat perbelanjaan modern Mall (jenis kelamin, usia, tingkat pendidikan, pekerjaan, pendapatan dan tempat tinggal (domisili) tidak memiliki hubungan terhadap perilaku perjalanannya (frekuensi, maksud, waktu). Meskipun demikian pada masing-masing Mall terdapat anomali pada variabel tertentu. Selain itu, sebagian besar atau rata-rata lebih dari $60 \%$ tarikan perjalanan masih berasal dari dalam KPY. Hal ini berarti bahwa secara morfologis, konsentrasi perkembangan fisik permukiman sebagai bangkitan masih relatif dekat dengan Mall sebagai tarikan. Perencanaan sistem transportasi massal yang dapat mengakomodir kebutuhan pergerakan ini harus dikembangkan dimasa datang sehingga kedekatan bangkitan dan tarikan tidak menimbulkan permasalahan transportasi seperti kemacetan, polusi udara, kebisisngan, dan lain sebagainya. Terlebih dengan adanya potensi bangkitan dari luar KPY maka pengembangan sistem transportasi ke pusat perbelanjaan modern sangat dibutuhkan.
Kutter (1973) menjelaskan bahwa pergerakan masyarakat perkotaan merupakan bagian dari pola aktivitas yang dilakukan oleh penduduk dalam era industrialisasi. Pergerakan masyarakat perkotaan berupa perjalanan untuk memenuhi kebutuhannya baik primer, sekunder, maupun tersier. Pergerakan masyarakat melalui pola perilaku perjalanan yang serupa menjadi kerangka pola aktivitas perkotaan. Berdasarkan hasil analisis, hubungan antara profil pelaku perjalanan terhadap perilaku perjalanannya menjadi representasi karakter pergerakan masyarakat KPY terhadap pusat kegiatan ekonomi. Dalam hal ini, faktor individual dianggap memiliki hubungan yang erat terhadap pola pergerakan. Hal-hal yang perlu dikembangkan dalam penelitian ke depan adalah mengeksplorasi lebih banyak variabel penelitian, jumlah sampel, dan data non agregat.

\section{Penghargaan}

Sebagian isi dari artikel ini adalah hasil penelitian Ratno Tanjung Nasrulloh Tahun 2016.

\section{Daftar Pustaka}

1. Arikunto, S. (2002). Prosedur suatu penelitian. Jakarta: Penerbit Rineka Cipta.

2. Boarnet, M., \& Crane, R. (2001). The influence of land use on travel behavior: specification and estimation strategies. Transportation Research Part A: Policy and Practice, 35(9), 823-845.

3. Kutter, E. (1973). A model for individual travel behaviour. Urban studies, 10(2), 235258.

4. Ulfa, I. M., \& Suwandono, D. (2014). Perilaku Perjalanan pada Akhir Pekan oleh Rumah Tangga yang Tinggal di Daerah Pinggiran Kota Semarang. Jurnal Pembangunan Wilayah \& Kota, 10(3), 343354.

5. Yunus, H. S. (2006). Struktur Tata Ruang Kota. cetakan ke IV. Yogyakarta: Pustaka Pelajar.

6. Zhou, B., \& Kockelman, K. M. (2008). Selfselection in home choice: Use of treatment effects in evaluating relationship between built environment and travel behavior. Transportation Research Record, 2077(1), 54-61. 
Hubungan Profil Pelaku Perjalanan Dengan Perilaku Perjalanan Terhadap Pusat Perbelanjaan Modern Di Kawasan

Perkotaan Yogyakarta

\section{Lampiran}

\section{Data Klasifikasi Mall Ambarukmo Plaza}

Hubungan Pendapatan dengan Frekuensi Kunjungan

\begin{tabular}{|c|c|c|c|c|c|c|c|}
\hline \multirow{2}{*}{ Frekuensi Kunjungan } & \multicolumn{6}{|c|}{ Pendapatan } & \multirow{2}{*}{ Total } \\
\hline & $<1$ juta & $1-2$ juta & 2-3 juta & 3-4 juta & 4-5 juta & $>5$ juta & \\
\hline 1x sebulan & 2 & 2 & 0 & 0 & 0 & 0 & 4 \\
\hline 2x sebulan & 0 & 1 & 1 & 0 & 0 & 0 & 2 \\
\hline $3 x$ sebulan & 1 & 0 & 2 & 0 & 0 & 0 & 3 \\
\hline lebih dari 3x sebulan & 0 & 3 & 1 & 1 & 1 & 2 & 8 \\
\hline tidak tentu & 2 & 6 & 3 & 1 & 2 & 1 & 15 \\
\hline Total & 5 & 12 & 7 & 2 & 3 & 3 & 32 \\
\hline
\end{tabular}

Hubungan Usia Dengan Frekuensi Kunjungan

\begin{tabular}{|l|c|c|c|c|}
\hline \multirow{2}{*}{ Frekuensi Kunjungan } & \multicolumn{3}{c|}{ Usia } & \multirow{2}{*}{ Total } \\
\cline { 2 - 5 } & $<20$ thn & $21-30$ thn & $31-40$ thn & 0 \\
\hline 1x sebulan & 1 & 3 & 0 & 2 \\
\hline 2x sebulan & 0 & 2 & 0 & 3 \\
\hline 3x sebulan & 1 & 2 & 1 & 8 \\
\hline lebih dari 3x sebulan & 2 & 5 & 4 & 15 \\
\hline tidak tentu Total & 3 & 8 & 5 & 32 \\
\hline \multicolumn{1}{|c|}{ Tyyynn} \\
\hline
\end{tabular}

Hubungan Pekerjaan Dengan Maksud Melakukan Perjalanan

\begin{tabular}{|l|c|c|c|c|c|c|}
\hline \multirow{2}{*}{\multicolumn{1}{c}{ Maksud Perjalanan }} & \multicolumn{2}{c|}{ Pekerjaan } & \multirow{2}{*}{ Total } \\
\cline { 2 - 7 } & Pelajar/Mahasiswa & Wiraswasta & IRT & Pegawai Swasta & PNS & \\
\hline Jalan-jalan & 11 & 5 & 0 & 2 & 1 & 19 \\
\hline Nonton bioskop & 1 & 0 & 0 & 0 & 0 & 1 \\
\hline Belanja sesuai rencana & 5 & 0 & 1 & 3 & 1 & 10 \\
\hline Lainnya & 0 & 0 & 0 & 2 & 0 & 2 \\
\hline \multicolumn{1}{|c|}{ Total } & 17 & 5 & 1 & 7 & 2 & 32 \\
\hline
\end{tabular}

Hubungan Domisili dengan Maksud Melakukan Perjalanan

\begin{tabular}{|l|c|c|c|c|c|c|}
\hline \multirow{2}{*}{ Maksud Perjalanan } & \multicolumn{4}{|c|}{ Domisili } & \multirow{2}{*}{ Total } \\
\cline { 2 - 7 } & Sleman & Yogyakarta & Bantul & Gunungkidul & Lainnya & 1 \\
\hline Jalan-jalan & 7 & 5 & 5 & 1 & 0 & 19 \\
\hline Nonton bioskop & 1 & 0 & 0 & 0 & 0 & 1 \\
\hline Belanja sesuai rencana & 5 & 3 & 2 & 0 & 0 & 2 \\
\hline Lainnya & 1 & 1 & 0 & 0 & 1 & 32 \\
\hline Total & 14 & 9 & 7 & 1 & & \\
\hline
\end{tabular}

Hubungan Domisili dengan Waktu Kunjungan

\begin{tabular}{|l|c|c|c|c|c|c|}
\multirow{2}{*}{\multicolumn{1}{c}{ Waktu Kunjungan }} & \multicolumn{5}{c|}{ Domisili } & \multirow{2}{*}{ Total } \\
\cline { 2 - 7 } & Sleman & Yogyakarta & Bantul & Gunungkidul & Lainnya & \\
\hline Akhir Pekan & 5 & 2 & 1 & 0 & 0 & 8 \\
\hline Sepulang Sekolah/Kuliah & 1 & 1 & 2 & 0 & 1 & 5 \\
\hline Waktu Luang & 7 & 5 & 4 & 1 & 0 & 17 \\
\hline Lainnya & 1 & 1 & 0 & 0 & 0 & 2 \\
\hline Total & 14 & 9 & 7 & 1 & 1 & 32 \\
\hline
\end{tabular}

Hubungan Pendapatan Dengan Maksud Melakukan Perjalanan

\begin{tabular}{|c|c|c|c|c|c|c|c|}
\hline \multirow{2}{*}{ Maksud Perjalanan } & \multicolumn{6}{|c|}{ Pendapatan } & \multirow{2}{*}{ Total } \\
\hline & $<1$ juta & $1-2$ juta & $2-3$ juta & $3-4$ juta & 4-5 juta & $>5$ juta & \\
\hline Jalan-jalan & 3 & 8 & 5 & 1 & 2 & 1 & 20 \\
\hline Belanja sesuai rencana & 4 & 3 & 1 & 0 & 1 & 0 & 9 \\
\hline
\end{tabular}

11 Sustainable, Planning and Culture (SPACE): Jurnal Perencanaan Wilayah dan Kota, Vol.2, No.2, Desember 2020 e-ISSN: 2656-7415 https://ejournal.unhi.ac.id/index.php/space 


\begin{tabular}{|c|c|c|c|c|c|c|c|}
\hline \multirow{2}{*}{ Maksud Perjalanan } & \multicolumn{6}{|c|}{ Pendapatan } & \multirow{2}{*}{ Total } \\
\hline & $<1$ juta & $1-2$ juta & 2-3 juta & 3-4 juta & 4-5 juta & $>5$ juta & \\
\hline Nonton bioskop & 0 & 0 & 0 & 1 & 1 & 0 & 2 \\
\hline Lainnya & 0 & 0 & 0 & 0 & 0 & 1 & 1 \\
\hline Total & 7 & 11 & 6 & 2 & 4 & 2 & 32 \\
\hline
\end{tabular}

Hubungan Pendapatan Dengan Maksud Melakukan Perjalanan

\begin{tabular}{|c|c|c|c|c|c|c|c|}
\hline \multirow{2}{*}{ Waktu Kunjungan } & \multicolumn{6}{|c|}{ Pendapatan } & \multirow{2}{*}{ Total } \\
\hline & $<1$ juta & $1-2$ juta & 2-3 juta & 3-4 juta & 4-5 juta & $>5$ juta & \\
\hline Waktu luang & 3 & 7 & 2 & 0 & 4 & 1 & 17 \\
\hline Sepulang sekolah/kuliah & 2 & 2 & 2 & 1 & 0 & 0 & 7 \\
\hline Akhir pekan & 2 & 2 & 2 & 0 & 0 & 0 & 6 \\
\hline Lainnya & 0 & 0 & 0 & 1 & 0 & 1 & 2 \\
\hline Total & 7 & 11 & 6 & 2 & 4 & 2 & 32 \\
\hline
\end{tabular}

Hubungan Pekerjaan dengan Frekuensi Kunjungan

\begin{tabular}{|c|c|c|c|c|c|c|}
\hline \multirow[b]{2}{*}{ Frekuensi Kunjungan } & \multicolumn{5}{|c|}{ Pekerjaan } & \multirow[b]{2}{*}{ Total } \\
\hline & Wiraswasta & $\begin{array}{c}\text { Pelajar/ } \\
\text { mahasiswa }\end{array}$ & Pegawai swasta & IRT & PNS & \\
\hline 1x sebulan & 1 & 3 & 0 & 0 & 0 & 4 \\
\hline 2x sebulan & 0 & 1 & 0 & 1 & 0 & 2 \\
\hline $3 x$ sebulan & 0 & 3 & 0 & 0 & 0 & 3 \\
\hline Lebih dari $3 \mathrm{x}$ sebulan & 0 & 5 & 1 & 0 & 1 & 7 \\
\hline Tidak tentu & 4 & 5 & 6 & 0 & 1 & 16 \\
\hline Total & 5 & 17 & 7 & 1 & 2 & 32 \\
\hline
\end{tabular}

Hubungan Pekerjaan dengan Waktu Kunjungan

\begin{tabular}{|l|c|c|c|c|c|c|}
\hline \multirow{2}{*}{ Waktu Kunjungan } & \multicolumn{3}{c|}{ Pekerjaan } & \multirow{2}{*}{ Total } \\
\cline { 2 - 6 } & Wiraswasta & $\begin{array}{c}\text { Pelajar/ } \\
\text { mahasiswa }\end{array}$ & Pegawai swasta & IRT & PNS & \\
\hline Waktu luang & 3 & 9 & 2 & 1 & 2 & 17 \\
\hline Sepulang sekolah/kuliah & 0 & 6 & 1 & 0 & 0 & 7 \\
\hline Akhir pekan & 2 & 1 & 1 & 0 & 0 & 6 \\
\hline Lainnya & 0 & 1 & 7 & 0 & 0 & 2 \\
\hline \multicolumn{1}{|c|}{ Total } & 5 & 17 & 1 & 2 & 32 \\
\hline
\end{tabular}

Hubungan Usia Dengan Maksud Melakukan Perjalanan

\begin{tabular}{|c|c|c|c|c|}
\hline \multirow{2}{*}{ Maksud Perjalanan } & \multicolumn{3}{|c|}{ Usia } & \multirow[b]{2}{*}{ Total } \\
\hline & $<20$ tahun & 20-30 tahun & $31-40$ tahun & \\
\hline Jalan-jalan & 7 & 11 & 2 & 20 \\
\hline Belanja sesuai rencana & 0 & 7 & 2 & 9 \\
\hline Nonton bioskop & 0 & 2 & 0 & 2 \\
\hline Lainnya & 0 & 0 & 1 & 1 \\
\hline Total & 7 & 20 & 5 & 32 \\
\hline
\end{tabular}

Hubungan Usia Dengan Waktu Kunjungan

\begin{tabular}{|c|c|c|c|c|}
\hline \multirow{2}{*}{ Waktu Kunjungan } & \multicolumn{3}{|c|}{ Usia } & \multirow[b]{2}{*}{ Total } \\
\hline & $<20$ tahun & 20-30 tahun & $31-40$ tahun & \\
\hline Waktu luang & 4 & 10 & 3 & 17 \\
\hline Sepulang sekolah/kuliah & 2 & 5 & 0 & 7 \\
\hline Akhir pekan & 1 & 4 & 1 & 6 \\
\hline Lainnya & 0 & 1 & 1 & 2 \\
\hline Total & 7 & 20 & 5 & 32 \\
\hline
\end{tabular}

Hubungan Domisili Dengan Frekuensi Kunjungan

\begin{tabular}{|l|c|c|c|c|c|c|}
\hline \multirow{2}{*}{ Frekuensi Kunjungan } & \multicolumn{5}{c|}{ Domisili } & \multirow{2}{*}{ Total } \\
\cline { 2 - 7 } & Gunung Kidul & Yogyakarta & Sleman & Bantul & Lainnya & \multirow{2}{*}{ 1x sebulan } \\
\hline 2x sebulan & 0 & 0 & 2 & 2 & 0 & 4 \\
\hline 3x sebulan & 0 & 0 & 1 & 1 & 0 & 2 \\
\hline
\end{tabular}

Sustainable, Planning and Culture (SPACE): Jurnal Perencanaan Wilayah dan Kota, Vol.2, No.2, Desember 202012 e-ISSN: 2656-7415 https://ejournal.unhi.ac.id/index.php/space 
Hubungan Profil Pelaku Perjalanan Dengan Perilaku Perjalanan Terhadap Pusat Perbelanjaan Modern Di Kawasan

Perkotaan Yogyakarta

\begin{tabular}{|c|c|c|c|c|c|c|}
\hline \multirow{2}{*}{ Frekuensi Kunjungan } & \multicolumn{5}{c|}{ Domisili } & \multirow{2}{*}{ Total } \\
\cline { 2 - 6 } & Gunung Kidul & Yogyakarta & Sleman & Bantul & Lainnya & 0 \\
\hline Lebih dari 3x sebulan & 0 & 3 & 3 & 1 & 0 & 7 \\
\hline Tidak tentu & 1 & 7 & 6 & 1 & 1 & 16 \\
\hline Total & 1 & 10 & 13 & 7 & 1 & 32 \\
\hline
\end{tabular}

2. Data Klasifikasi Silang Lippo Mall

Hubungan Pendapatan dengan Frekuensi Kunjungan

\begin{tabular}{|c|c|c|c|c|c|c|c|}
\hline \multirow{2}{*}{ Frekuensi Kunjungan } & \multicolumn{6}{|c|}{ Pendapatan } & \multirow{2}{*}{ Total } \\
\hline & $<1$ juta & $1-2$ juta & 2-3 juta & 3-4 juta & 4-5 juta & $>5$ juta & \\
\hline 1x sebulan & 2 & 1 & 2 & 0 & 0 & 0 & 5 \\
\hline 2x sebulan & 0 & 3 & 2 & 1 & 0 & 0 & 6 \\
\hline 3x sebulan & 1 & 1 & 1 & 2 & 0 & 1 & 6 \\
\hline lebih dari 3x sebulan & 0 & 0 & 1 & 0 & 1 & 0 & 2 \\
\hline tidak tentu & 1 & 5 & 5 & 2 & 0 & 0 & 13 \\
\hline Total & 4 & 10 & 11 & 5 & 1 & 1 & 32 \\
\hline
\end{tabular}

Hubungan Usia dengan Frekuensi Kunjungan

\begin{tabular}{|c|c|c|c|c|c|}
\hline \multirow{2}{*}{ Frekuensi Kunjungan } & \multicolumn{4}{|c|}{ Usia } & \multirow{2}{*}{ Total } \\
\hline & $<20$ thn & $21-30$ thn & $31-40$ thn & $<40$ thn & \\
\hline 1x sebulan & 2 & 0 & 3 & 0 & 5 \\
\hline 2x sebulan & 3 & 3 & 0 & 0 & 6 \\
\hline $3 x$ sebulan & 2 & 3 & 1 & 0 & 6 \\
\hline lebih dari $3 x$ sebulan & 0 & 2 & 0 & 0 & 2 \\
\hline tidak tentu & 6 & 2 & 4 & 1 & 13 \\
\hline Total & 13 & 10 & 8 & 1 & 32 \\
\hline
\end{tabular}

Hubungan Pekerjaan dengan Maksud Melakukan Perjalanan

\begin{tabular}{|c|c|c|c|c|c|c|}
\hline \multirow{2}{*}{ Maksud Perjalanan } & \multicolumn{4}{|c|}{ Pekerjaan } & & \multirow{2}{*}{ Total } \\
\hline & Pelajar/Mahasiswa & Pegawai Swasta & Wiraswasta & PNS & IRT & \\
\hline Jalan-jalan & 4 & 1 & 2 & 0 & 1 & 8 \\
\hline Makan & 2 & 2 & 0 & 1 & 0 & 5 \\
\hline Nonton bioskop & 9 & 0 & 0 & 0 & 0 & 9 \\
\hline Belanja sesuai rencana & 1 & 2 & 3 & 1 & 3 & 10 \\
\hline Total & 16 & 5 & 5 & 2 & 4 & 32 \\
\hline
\end{tabular}

Hubungan Domisili dengan Maksud Melakukan Perjalanan

\begin{tabular}{|c|c|c|c|c|c|}
\hline \multirow{2}{*}{ Maksud Perjalanan } & \multicolumn{4}{|c|}{ Domisili } & \multirow{2}{*}{ Total } \\
\hline & Sleman & Yogyakarta & Bantul & Gunungkidul & \\
\hline Jalan-jalan & 4 & 3 & 1 & 0 & 8 \\
\hline Makan & 0 & 3 & 2 & 0 & 5 \\
\hline Nonton bioskop & 4 & 1 & 4 & 0 & 9 \\
\hline Belanja sesuai rencana & 3 & 3 & 3 & 1 & 10 \\
\hline Total & 11 & 10 & 10 & 1 & 32 \\
\hline
\end{tabular}

Hubungan Domisili dengan Waktu Kunjungan

\begin{tabular}{|c|c|c|c|c|c|}
\hline \multirow{2}{*}{ Waktu Kunjungan } & \multicolumn{4}{|c|}{ Domisili } & \multirow{2}{*}{ Total } \\
\hline & Sleman & Yogyakarta & Bantul & Gunungkidul & \\
\hline Akhir Pekan & 1 & 1 & 1 & 0 & 3 \\
\hline Sepulang Kerja & 0 & 2 & 2 & 0 & 4 \\
\hline Sepulang Sekolah/Kuliah & 2 & 0 & 2 & 0 & 4 \\
\hline Waktu Luang & 7 & 7 & 5 & 1 & 20 \\
\hline Lainnya & 1 & 0 & 0 & 0 & 1 \\
\hline Total & 11 & 10 & 10 & 1 & 32 \\
\hline
\end{tabular}

Hubungan Pendapatan dengan Maksud Melakukan Perjalanan

13 Sustainable, Planning and Culture (SPACE): Jurnal Perencanaan Wilayah dan Kota, Vol.2, No.2, Desember 2020 e-ISSN: 2656-7415 https://ejournal.unhi.ac.id/index.php/space 


\begin{tabular}{|c|c|c|c|c|c|c|c|}
\hline \multirow{2}{*}{ Maksud Perjalanan } & \multicolumn{6}{|c|}{ Pendapatan } & \multirow{2}{*}{ Total } \\
\hline & $<1$ juta & $1-2$ juta & $2-3$ juta & 3-4 juta & 4-5 juta & $>5$ juta & \\
\hline Jalan-jalan & 2 & 1 & 4 & 0 & 1 & 0 & 8 \\
\hline Belanja sesuai rencana & 1 & 2 & 4 & 3 & 0 & 0 & 10 \\
\hline Nonton bioskop & 1 & 6 & 1 & 0 & 0 & 1 & 9 \\
\hline Lainnya & 0 & 1 & 2 & 2 & 0 & 0 & 5 \\
\hline Total & 4 & 10 & 11 & 5 & 1 & 1 & 32 \\
\hline
\end{tabular}

Hubungan Pendapatan Dengan Waktu Kunjungan

\begin{tabular}{|c|c|c|c|c|c|c|c|}
\hline \multirow{2}{*}{ Waktu Kunjungan } & \multicolumn{6}{|c|}{ Pendapatan } & \multirow{2}{*}{ Total } \\
\hline & $<1$ juta & $1-2$ juta & $2-3$ juta & 3-4 juta & 4-5 juta & $>5$ juta & \\
\hline Waktu luang & 2 & 5 & 8 & 4 & 0 & 1 & 20 \\
\hline Sepulang sekolah/kuliah & 0 & 4 & 0 & 0 & 0 & 0 & 4 \\
\hline Akhir pekan & 1 & 0 & 1 & 1 & 0 & 0 & 3 \\
\hline Lainnya & 1 & 0 & 0 & 0 & 0 & 0 & 1 \\
\hline Sepulang kerja & 0 & 1 & 2 & 0 & 1 & 0 & 4 \\
\hline
\end{tabular}

Hubungan Pekerjaan dengan Frekuensi Kunjungan

\begin{tabular}{|l|c|c|c|c|c|c|}
\hline \multirow{2}{*}{ Frekuensi Kunjungan } & \multicolumn{3}{c|}{ Hubungan Pekerjaan dengan Frekuensi Kunjungan } & \multirow{2}{*}{ Total } \\
\cline { 2 - 7 } & Wiraswasta & Pelajar/mahasiswa & Pegawai swasta & IRT & PNS & \\
\hline 1x sebulan & 0 & 1 & 1 & 3 & 0 & 5 \\
\hline 2x sebulan & 0 & 5 & 0 & 0 & 0 & 5 \\
\hline 3x sebulan & 2 & 4 & 0 & 0 & 1 & 7 \\
\hline Lebih dari 3x sebulan & 0 & 1 & 1 & 0 & 0 & 2 \\
\hline Tidak tentu & 2 & 6 & 2 & 1 & 2 & 13 \\
\hline \multicolumn{1}{c|}{ Total } & 4 & 17 & 4 & 3 & 32 \\
\hline
\end{tabular}

Hubungan Pekerjaan dengan Waktu Kunjungan

\begin{tabular}{|l|c|c|c|c|c|c|}
\hline \multirow{2}{*}{ Waktu Kunjungan } & \multicolumn{5}{c|}{ Pekerjaan } & \multirow{2}{*}{ Total } \\
\cline { 2 - 6 } & Wiraswasta & Pelajar/mahasiswa & Pegawai swasta & IRT & PNS & \\
\hline Waktu luang & 3 & 11 & 2 & 3 & 1 & 20 \\
\hline Sepulang sekolah/kuliah & 0 & 4 & 0 & 0 & 0 & 4 \\
\hline Akhir pekan & 0 & 2 & 0 & 0 & 1 & 3 \\
\hline Lainnya & 0 & 0 & 2 & 1 & 0 & 1 \\
\hline Sepulang Kerja & 1 & 0 & 4 & 0 & 1 & 4 \\
\hline \multicolumn{1}{c}{ Total } & 4 & 17 & 4 & 3 & 32 \\
\hline
\end{tabular}

Hubungan Usia Dengan Maksud Melakukan Perjalanan

\begin{tabular}{|l|c|c|c|c|c|}
\hline \multirow{2}{*}{ Maksud Perjalanan } & \multicolumn{2}{c|}{ Usia } & \multicolumn{2}{c|}{ Total } \\
\cline { 2 - 6 } & $<20$ tahun & $20-30$ tahun & $31-40$ tahun & $>40$ tahun & 8 \\
\hline Jalan-jalan & 3 & 5 & 0 & 0 & 1 \\
\hline Belanja sesuai rencana & 2 & 1 & 6 & 0 & 9 \\
\hline Nonton bioskop & 8 & 1 & 0 & 0 & 5 \\
\hline Lainnya Total & 0 & 3 & 2 & 1 & 32 \\
\hline \multicolumn{2}{c|}{$\quad 13$} & 10 & 8 & & 1 \\
\hline
\end{tabular}

Hubungan Usia Dengan Waktu Kunjungan

\begin{tabular}{|l|c|c|c|c|c|}
\hline \multirow{2}{*}{ Waktu Kunjungan } & \multicolumn{3}{c|}{ Usia } & \multirow{2}{*}{ Total } \\
\cline { 2 - 6 } & $<20$ tahun & $20-30$ tahun & $31-40$ tahun & $>40$ tahun & 20 \\
\hline Waktu luang & 7 & 7 & 5 & 1 & 0 \\
\hline Sepulang sekolah/kuliah & 4 & 0 & 0 & 0 & 3 \\
\hline Akhir pekan & 1 & 1 & 1 & 0 & 1 \\
\hline Lainnya & 1 & 0 & 0 & 0 & 4 \\
\hline Sepulang kerja Total & 0 & 2 & 2 & 1 & 32 \\
\hline \multicolumn{2}{|c|}{} \\
\hline
\end{tabular}

Hubungan Domisili dengan Frekuensi Kunjungan

\begin{tabular}{|l|c|c|c|c|c|}
\hline \multirow{2}{*}{ Frekuensi Kunjungan } & \multicolumn{3}{|c|}{ Domisili } & \multirow{2}{*}{ Total } \\
\cline { 2 - 6 } & Gunung Kidul & Yogyakarta & Sleman & 2 & 5 \\
\hline
\end{tabular}

Sustainable, Planning and Culture (SPACE): Jurnal Perencanaan Wilayah dan Kota, Vol.2, No.2, Desember 202014 e-ISSN: 2656-7415 https://ejournal.unhi.ac.id/index.php/space 
Hubungan Profil Pelaku Perjalanan Dengan Perilaku Perjalanan Terhadap Pusat Perbelanjaan Modern Di Kawasan

Perkotaan Yogyakarta

\begin{tabular}{|l|c|c|c|c|c|}
\hline \multirow{2}{*}{ Frekuensi Kunjungan } & \multicolumn{3}{c|}{ Domisili } & \multirow{2}{*}{ Total } \\
\cline { 2 - 6 } & Gunung Kidul & Yogyakarta & Sleman & Bantul & 5 \\
\hline 2x sebulan & 0 & 1 & 2 & 2 & 7 \\
\hline 3x sebulan & 0 & 3 & 1 & 0 & 2 \\
\hline Lebih dari 3x sebulan & 0 & 1 & 5 & 4 & 13 \\
\hline Tidak tentu Total & 0 & 4 & 11 & 10 & 32 \\
\hline \multicolumn{2}{|r|}{} \\
\hline
\end{tabular}

3. Data Klasifikasi Silang Jogja City Mall

Hubungan Pendapatan dengan Frekuensi Kunjungan

\begin{tabular}{|c|c|c|c|c|c|c|c|}
\hline \multirow{2}{*}{ Frekuensi Kunjungan } & \multicolumn{6}{|c|}{ Pendapatan } & \multirow{2}{*}{ Total } \\
\hline & $<1$ juta & $1-2$ juta & $2-3$ juta & $3-4$ juta & $4-5$ juta & $>5$ juta & \\
\hline 1x sebulan & 3 & 0 & 0 & 0 & 0 & 1 & 4 \\
\hline 2x sebulan & 1 & 2 & 1 & 1 & 0 & 0 & 5 \\
\hline $3 x$ sebulan & 1 & 0 & 2 & 2 & 0 & 0 & 5 \\
\hline lebih dari 3x sebulan & 2 & 2 & 1 & 0 & 1 & 1 & 7 \\
\hline tidak tentu & 4 & 4 & 1 & 1 & 1 & 0 & 11 \\
\hline Total & 11 & 8 & 5 & 4 & 2 & 2 & 32 \\
\hline
\end{tabular}

Hubungan Usia dengan Frekuensi Kunjungan

\begin{tabular}{|l|c|c|c|c|c|}
\hline \multirow{2}{*}{ Frekuensi Kunjungan } & \multicolumn{2}{c|}{ Usia } & \multirow{2}{*}{ Total } \\
\cline { 2 - 6 } & $<20$ thn & $21-30$ thn & $31-40$ thn & $>40$ thn & 4 \\
\hline 1x sebulan & 2 & 2 & 0 & 0 & 0 \\
\hline 2x sebulan & 1 & 3 & 1 & 0 & 5 \\
\hline 3x sebulan & 0 & 4 & 1 & 0 & 7 \\
\hline lebih dari 3x sebulan & 0 & 6 & 1 & 1 & 11 \\
\hline tidak tentu & 5 & 4 & 1 & 1 & 32 \\
\hline \multicolumn{1}{|c|}{ Total } & 8 & 19 & 4 & & 1 \\
\hline
\end{tabular}

Hubungan Pekerjaan dengan Maksud Melakukan Perjalanan

\begin{tabular}{|l|c|c|c|c|c|c|c|}
\hline \multirow{2}{*}{ Maksud Perjalanan } & \multicolumn{5}{|c|}{ Pekerjaan } & \multirow{2}{*}{ Total } \\
\cline { 2 - 8 } & $\begin{array}{c}\text { Pelajar/ } \\
\text { Mahasiswa }\end{array}$ & Wiraswasta & IRT & Pegawai Swasta & PNS & Lainnya & \\
\hline Jalan-jalan & 8 & 2 & 0 & 3 & 2 & 1 & 16 \\
\hline Makan & 2 & 0 & 0 & 0 & 1 & 0 & 3 \\
\hline Nonton bioskop & 3 & 0 & 1 & 0 & 1 & 0 & 5 \\
\hline Belanja sesuai rencana & 3 & 1 & 1 & 1 & 0 & 0 & 6 \\
\hline Lainnya & 0 & 0 & 0 & 1 & 1 & 0 & 2 \\
\hline \multicolumn{1}{|c|}{ Total } & 16 & 3 & 2 & 5 & 5 & 1 & 32 \\
\hline
\end{tabular}

Hubungan Domisili dengan Maksud Melakukan Perjalanan

\begin{tabular}{|c|c|c|c|c|c|c|}
\hline \multirow{2}{*}{ Maksud Perjalanan } & \multicolumn{5}{|c|}{ Domisili } & \multirow{2}{*}{ Total } \\
\hline & Sleman & Yogyakarta & Kulonprogo & Bantul & Lainnya & \\
\hline Jalan-jalan & 9 & 5 & 0 & 0 & 2 & 16 \\
\hline Makan & 1 & 0 & 2 & 0 & 0 & 3 \\
\hline Nonton bioskop & 3 & 1 & 0 & 1 & 0 & 5 \\
\hline Belanja sesuai rencana & 3 & 3 & 0 & 0 & 0 & 6 \\
\hline Lainnya & 1 & 0 & 1 & 0 & 0 & 2 \\
\hline Total & 17 & 9 & 3 & 1 & 2 & 32 \\
\hline
\end{tabular}

Hubungan Domisili dengan Waktu Kunjungan

\begin{tabular}{|c|c|c|c|c|c|c|}
\hline \multirow{2}{*}{ Waktu Kunjungan } & \multicolumn{5}{|c|}{ Domisili } & \multirow{2}{*}{ Total } \\
\hline & Sleman & Yogyakarta & Kulonprogo & Bantul & Lainnya & \\
\hline Akhir Pekan & 4 & 2 & 0 & 0 & 0 & 6 \\
\hline Sepulang Kerja & 1 & 2 & 1 & 0 & 0 & 4 \\
\hline Sepulang Sekolah/Kuliah & 1 & 0 & 0 & 0 & 1 & 2 \\
\hline Waktu Luang & 9 & 5 & 2 & 1 & 1 & 18 \\
\hline Lainnya & 2 & 0 & 0 & 0 & 0 & 2 \\
\hline
\end{tabular}




\begin{tabular}{|l|c|c|c|c|c|c|}
\hline \multirow{2}{*}{ Waktu Kunjungan } & \multicolumn{4}{|c|}{ Domisili } & \multirow{2}{*}{ Total } \\
\cline { 2 - 7 } & Sleman & Yogyakarta & Kulonprogo & Bantul & Lainnya & 2 \\
\hline Total & 17 & 9 & 3 & 1 & 2 & 32 \\
\hline
\end{tabular}

Hubungan Pendapatan Dengan Maksud Melakukan Perjalanan

\begin{tabular}{|c|c|c|c|c|c|c|c|}
\hline \multirow{2}{*}{ Maksud Perjalanan } & \multicolumn{6}{|c|}{ Pendapatan } & \multirow{2}{*}{ Total } \\
\hline & $<1$ juta & $1-2$ juta & $2-3$ juta & 3- 4 juta & $4-5$ juta & $>5$ juta & \\
\hline Jalan-jalan & 6 & 5 & 4 & 1 & 1 & 0 & 17 \\
\hline Belanja sesuai rencana & 2 & 3 & 0 & 1 & 0 & 0 & 6 \\
\hline Nonton bioskop & 2 & 0 & 1 & 0 & 1 & 0 & 4 \\
\hline Lainnya & 0 & 0 & 0 & 1 & 0 & 1 & 2 \\
\hline Makan & 1 & 0 & 0 & 1 & 0 & 1 & 3 \\
\hline Total & 11 & 8 & 5 & 4 & 2 & 2 & 32 \\
\hline
\end{tabular}

HubunganPendapatan denganWaktu Kunjungan

\begin{tabular}{|c|c|c|c|c|c|c|c|}
\hline \multirow{2}{*}{ Waktu Kunjungan } & \multicolumn{6}{|c|}{ Pendapatan } & \multirow{2}{*}{ Tota } \\
\hline & $<1$ juta & $1-2$ juta & $2-3$ juta & 3-4 juta & 4-5 juta & $>5$ juta & \\
\hline Waktu luang & 5 & 6 & 4 & 1 & 1 & 1 & 18 \\
\hline Sepulang sekolah/kuliah & 1 & 1 & 0 & 0 & 0 & 0 & 2 \\
\hline Akhir pekan & 5 & 1 & 0 & 0 & 0 & 0 & 6 \\
\hline Lainnya & 0 & 0 & 0 & 1 & 1 & 0 & 2 \\
\hline Sepulang kerja & 0 & 0 & 1 & 2 & 0 & 1 & 4 \\
\hline Total & 11 & 8 & 5 & 4 & 2 & 2 & 32 \\
\hline
\end{tabular}

Hubungan Pekerjaan dengan Frekuensi Kunjungan

\begin{tabular}{|c|c|c|c|c|c|c|c|}
\hline \multirow[b]{2}{*}{ Frekuensi Kunjungan } & \multicolumn{6}{|c|}{ Pekerjaan } & \multirow[b]{2}{*}{ Total } \\
\hline & $\begin{array}{c}\text { Wira } \\
\text { swasta }\end{array}$ & $\begin{array}{c}\text { Pelajar/ } \\
\text { mahasiswa }\end{array}$ & Pegawai swasta & IRT & PNS & Lainnya & \\
\hline 1x sebulan & 0 & 3 & 0 & 0 & 1 & 0 & 4 \\
\hline $2 \mathrm{x}$ sebulan & 1 & 2 & 2 & 0 & 0 & 0 & 5 \\
\hline $3 x$ sebulan & 0 & 2 & 2 & 0 & 1 & 0 & 5 \\
\hline Lebih dari 3x sebulan & 0 & 4 & 0 & 1 & 1 & 1 & 7 \\
\hline Tidak tentu & 2 & 5 & 1 & 1 & 2 & 0 & 11 \\
\hline Total & 3 & 16 & 5 & 2 & 5 & 1 & 32 \\
\hline
\end{tabular}

Hubungan Pekerjaan dengan Waktu Kunjungan

\begin{tabular}{|c|c|c|c|c|c|c|c|}
\hline \multirow[b]{2}{*}{ Waktu Kunjungan } & \multicolumn{6}{|c|}{ Pekerjaan } & \multirow[b]{2}{*}{ Total } \\
\hline & $\begin{array}{c}\text { Wira } \\
\text { swasta }\end{array}$ & $\begin{array}{c}\text { Pelajar/ } \\
\text { mahasiswa }\end{array}$ & Pegawai swasta & IRT & PNS & Lainnya & \\
\hline Waktu luang & 2 & 9 & 2 & 1 & 3 & 1 & 18 \\
\hline Sepulang sekolah/kuliah & 0 & 2 & 0 & 0 & 0 & 0 & 2 \\
\hline Akhir pekan & 1 & 5 & 0 & 0 & 0 & 0 & 6 \\
\hline Lainnya & 0 & 0 & 1 & 1 & 0 & 0 & 2 \\
\hline Sepulang Kerja & 0 & 0 & 2 & 0 & 2 & 0 & 4 \\
\hline Total & 3 & 16 & 5 & 2 & 5 & 1 & 32 \\
\hline
\end{tabular}

Hubungan Usia Dengan Maksud Melakukan Perjalanan

\begin{tabular}{|c|c|c|c|c|c|}
\hline \multirow{2}{*}{ Maksud Perjalanan } & \multicolumn{4}{|c|}{ Usia } & \multirow[b]{2}{*}{ Total } \\
\hline & $<20$ tahun & 20-30 tahun & $31-40$ tahun & $>40$ tahun & \\
\hline Jalan-jalan & 5 & 8 & 4 & 0 & 17 \\
\hline Belanja sesuai rencana & 1 & 4 & 1 & 0 & 6 \\
\hline Nonton bioskop & 2 & 1 & 0 & 1 & 4 \\
\hline Lainnya & 0 & 2 & 0 & 0 & 2 \\
\hline Makan & 0 & 3 & 0 & 0 & 3 \\
\hline Total & 8 & 18 & 5 & 1 & 32 \\
\hline
\end{tabular}

Hubungan Usia Dengan Waktu Kunjungan

\begin{tabular}{|c|c|c|c|c|c|}
\hline \multirow{2}{*}{ Waktu Kunjungan } & \multicolumn{4}{|c|}{ Usia } & \multirow[b]{2}{*}{ Total } \\
\hline & $<20$ tahun & $20-30$ tahun & $31-40$ tahun & $>40$ tahun & \\
\hline Waktu luang & 3 & 11 & 3 & 1 & 18 \\
\hline
\end{tabular}

Sustainable, Planning and Culture (SPACE): Jurnal Perencanaan Wilayah dan Kota, Vol.2, No.2, Desember 202016 e-ISSN: 2656-7415 https://ejournal.unhi.ac.id/index.php/space 
Hubungan Profil Pelaku Perjalanan Dengan Perilaku Perjalanan Terhadap Pusat Perbelanjaan Modern Di Kawasan Perkotaan Yogyakarta

\begin{tabular}{|c|c|c|c|c|c|}
\hline \multirow{2}{*}{ Waktu Kunjungan } & \multicolumn{4}{|c|}{ Usia } & \multirow[b]{2}{*}{ Total } \\
\hline & $<20$ tahun & 20-30 tahun & $31-40$ tahun & $>40$ tahun & \\
\hline Sepulang sekolah/kuliah & 2 & 0 & 0 & 0 & 2 \\
\hline Akhir pekan & 3 & 3 & 0 & 0 & 6 \\
\hline Lainnya & 0 & 1 & 1 & 0 & 2 \\
\hline Sepulang kerja & 0 & 3 & 1 & 0 & 4 \\
\hline Total & 8 & 18 & 5 & 1 & 32 \\
\hline
\end{tabular}

Hubungan Domisili Dengan Frekuensi Kunjungan

\begin{tabular}{|c|c|c|c|c|c|c|}
\hline \multirow{2}{*}{ Frekuensi Kunjungan } & \multicolumn{5}{|c|}{ Domisili } & \multirow{2}{*}{ Tota } \\
\hline & Yogyakarta & Sleman & Bantul & Lainnya & Kulonprogo & \\
\hline 1x sebulan & 0 & 2 & 1 & 0 & 1 & 4 \\
\hline 2x sebulan & 2 & 3 & 0 & 0 & 0 & 6 \\
\hline $3 x$ sebulan & 1 & 4 & 0 & 0 & 0 & 5 \\
\hline Lebih dari 3x sebulan & 2 & 3 & 0 & 1 & 1 & 7 \\
\hline Tidak tentu & 4 & 4 & 2 & 1 & 0 & 11 \\
\hline Total & 9 & 16 & 3 & 2 & 2 & 32 \\
\hline
\end{tabular}

